\title{
Áreas limpas: estudo de correlação entre partículas viáveis e não-viáveis
}

\author{
Catherine Simões de Abreu ${ }^{1 *}$, Terezinha de Jesus Andreoli Pinto ${ }^{2}$, Débora Cristina de Oliveira ${ }^{2}$
}

'Eli Lilly do Brasil; ${ }^{2}$ Departamento de Farmácia, Faculdade de Ciências Farmacêuticas da Universidade de São Paulo.

*Correspondência:

C.S. Abreu

Departamento de Farmácia

Faculdade de Ciências Farmacêuticas USP

Av. Prof Lineu Prestes, 580 - Butantã

05508-900 - São Paulo - SP

E-mail:

abreu_catherine_simoes@lilly.com
Este trabalho consiste em um estudo sobre monitoramento ambiental de áreas limpas (classes $A, B, C$ e D). Os parâmetros comparados foram partículas não-viáveis de 0,5 e 5,0 $\mu \mathrm{m}$ e de viáveis em UFC (unidades formadoras de colonias), do ambiente e de superficies $\left(\right.$ Rodac $\left.^{\circledR}\right)$. As amostragens nas áreas limpas foram feitas em situações de repouso e dinâmica, antes e após sanitização, e em etapas de certificação e rotina. Os dados de literatura indicam que os parâmetros não são particularmente dependentes do lay out ou classificação das áreas, mas sim do seu uso e do comportamento dos operadores. As conclusões foram positivas quanto à correlação entre diferentes locais de amostragem, para partículas não viáveis de 0,5 e 5,0 $\mu \mathrm{m}$, caracterizando-se, porém, ausência deste tipo de correlação nas posições em fluxo laminar. Também, os valores de correlação foram quase sempre decrescentes com a maior limpeza do ambiente. Os microrganismos mais freqüentemente isolados nas áreas $B, C$ e $D$ foram Bacillus $s p$, Staphylococcus $s p$ e Corynebacterium $s p$.
Unitermos:

- Salas limpas

- Monitoramento ambiental

- Partículas viáveis

- Partículas não-viáveis

- Microrganismos

\section{INTRODUÇÃO}

A produção de medicamentos tem sido aperfeiçoada com o passar dos anos, nos diferentes aspectos. Itens inerentes à aprovação dos procedimentos abrangem a certificação de ambientes, validação de processos, objetivando sempre a obtenção de produtos que atendam à especificação e nos quais estejam implícitos os itens de qualidade pertinentes. Em se tratando de produtos farmacêuticos, a qualidade e eficácia são quesitos indispensáveis, daí a importância em se avaliar a presença, quantificar e identificar as partículas viáveis.

O objetivo deste trabalho consistiu em comparar o número de partículas não-viáveis e viáveis (contaminação microbiana) em salas limpas, a fim de investigar a correlação entre as mesmas. Ainda, o trabalho avaliou o efeito da sanitização e da cinética da sala, caracterizando situações de repouso ou dinâmica, além do número de partículas nãoviáveis e viáveis de salas limpas com distintas classes. Procedeu-se, também, à identificação das espécies microbianas encontradas e ao estudo de freqüências de detecção destas.

\section{MATERIAL E MÉTODO}

\section{Material}

O material de estudo para o presente trabalho constituiu-se em partículas viáveis ou não, amostradas em am- 
bientes de áreas limpas classes A, B, C e D (U.S.Depart. Health Human Serv., 2002), assim como partículas viáveis presentes em suas superfícies. Os momentos de amostragem abrangem situações denominadas de Qualificação e Rotina 1, assim como Qualificação e Rotina 2.

\section{Método}

\section{Amostragem e Quantificação de Partículas}

O método abrangeu um programa de monitoramento ambiental e foi iniciado imediatamente após finalizado o acabamento das etapas de edificação.

Trabalhou-se em primeira instância (Qualificação 1) conforme o Federal Standard 209 E, em fase at rest. Num segundo momento (Qualificação 2) seguiu-se a recomendação do Institute of Environmental Sciences and Technology - Contamination Control Division com as salas, nas seguintes situações: conforme construída (as built), em repouso (at rest) e em operação (dynamic).

O programa de monitoramento ambiental envolveu grande número de atividades, entre as quais a Qualificação da Área. Tal qualificação consistiu em gerar provas documentais de que o sistema de ar filtrado e condicionado trabalha de maneira consistente, em consonância com os procedimentos de limpeza, assepsia e outros, no sentido de assegurar um ambiente apropriado para a fabricação de produtos estéreis.

A Qualificação da Área envolveu a determinação de matriz de amostragem (Grid) conforme orientação de normas internacionais, particularmente o Federal Standard 209E - Airborne Particulate Cleanliness Classes in Cleanrooms and Clean Zones (Inst. Envir. Sc., 1992) e o IEST - Institute of Environmental Sciences and Technology (Inst. Envir. Sc. Tech., 1992). A definição da matriz teve por base a área de cada sala ou região a ser estudada e a classificação teórica. A amostragem foi geralmente realizada no centro de cada quadrado imaginário do Grid. No entanto, ocorreram casos em que algum fator limitante determinou o deslocamento da amostragem para um dos cantos do quadrado imaginário.

Amostras de cada quadrado permitiram a determinação do número de partículas não-viáveis presentes na área e mesmo das partículas viáveis (microrganismos), classificando-a. Dois tamanhos de partículas foram selecionados para o monitoramento, 0,5 e $5,0 \mu \mathrm{m}$, atendendo as normas internacionais.

A quantificação das partículas viáveis torna implícita a necessidade do emprego de placas contendo meio de cultura sobre as quais se faz impactar o volume de ar amostrado. Adicionalmente, é necessária a incubação do meio de cultura após a amostragem, de forma a permitir a visualização das colônias microbianas provenientes da amostra coletada. Todas as placas para contagem de partículas viáveis foram incubadas a $20-25^{\circ} \mathrm{C}$, por 2 dias, e a $30-35^{\circ} \mathrm{C}$, por mais 3 dias, totalizando 5 dias de incubação, em estufas validadas.

O meio de cultura utilizado neste trabalho foi o ágar caseína soja (Difco) acrescido de $0,1 \%$ de lecitina de soja e $0,7 \%$ de tween 80 para a inativação de resíduos de sanitizantes, e $10 \mathrm{~mL}$ de penicilinase por litro de meio de cultura para a inativação de resíduos de antibióticos cefalosporânicos.

\section{Amostragem ativa de ar para determinação de partículas não-viáveis}

$\mathrm{O}$ procedimento de amostragem foi realizado empregando os equipamentos das marcas Biotest ${ }^{\circledR} \mathrm{e}$ MetOne $^{\circledR}$.

$\mathrm{O}$ contador de partículas da marca Biotest ${ }^{\mathrm{B}}$, modelo APC 1000, amostrou volume correspondente a 1 pé cúbico, o que demandou em tempo de amostragem de $10 \mathrm{mi}-$ nutos. O contador de partículas da marca MetOne ${ }^{\circledR}$ modelo 3113 permite a captação de 1 pé cúbico de ar por minuto, portanto a amostragem com este equipamento correspondeu ao tempo de apenas 1 minuto.

\section{Amostragem ativa de ar para determinação de partículas viáveis}

Neste trabalho foi utilizado amostrador ativo de ar (PBI ${ }^{\circledR}$, modelo SAS Super 90), seguindo o princípio da impactação, tendo sido amostrados volumes de 1000 litros de ar nas posições internas aos fluxos laminares (área A) e de 500 litros de ar nas demais posições (áreas B, C e D). A operação consistiu em inserir individualmente no equipamento placas Rodac ${ }^{\circledR}$ contendo meio de cultura ágar caseína soja. Após as amostragens de ar as placas foram retiradas e incubadas, seguido-se contagem das unidades formadoras de colônia (UFC).

Amostragem de superfícies para partículas viáveis A amostragem foi realizada com o auxílio de placas Rodac ${ }^{\circledR}$ contendo meio de cultura (ágar caseína soja) usadas para o contato com a superfície a ser amostrada, por período de tempo de aproximadamente 5 segundos sob leve pressão. Após incubação desta placa procedeu-se à contagem das UFC.

\section{Identificação dos microrganismos contaminantes}

A identificação dos microrganismos obtidos nas amostragens de superfícies foi efetuada empregando-se equipamento BioMeriéux Vitek ${ }^{\circledR}$, que consiste em sistema automatizado para identificação de bactérias e fungos. As 
unidades de leitura são conhecidas como cartões, cujas respostas bioquímicas conduzem às leituras específicas de variações colorimétricas e de turbidez.

\section{RESULTADOS E DISCUSSÃO}

Entre as fontes contaminantes potenciais de áreas limpas, selecionaram-se para estudos aquelas decorrentes do ambiente produtivo. Assim, procedeu-se à determinação quantitativa de partículas não-viáveis de 0,5 e 5,0 $\mu \mathrm{m}$ assim como de partículas viáveis provenientes do ar (ambiente) e as partículas viáveis de superfícies $\left(\operatorname{Rodac}^{\circledR}\right)$, sempre buscando respeitar o melhor possível as localizações geográficas.

Um dos fatores de variação considerados no estudo foi a classe, que indica locais com exigências específicas de qualidade ambiental, conforme critérios do Federal Standard 209 E (Inst. Envir. Sc., 1992) e IEST (Inst. Envir. Sc. Tech.,1992). A base de classificação é função do número de partículas não-viáveis e viáveis do ambiente e viáveis da superfície (Tabela III). Cada classe foi representada por distintas salas e cada sala por distintos pontos de coleta de amostras.

Embora o trabalho tenha contemplado quatro mo- mentos (antes e após sanitização, situação dinâmica e em repouso), sendo respectivamente Qualificação e Rotina 1 e Qualificação e Rotina 2, em decorrência da ausência de dados de partículas viáveis e de poucos dados de partículas não-viáveis no momento denominado Qualificação 1, a análise estatística não abrangeu os resultados gerados neste momento.

A avaliação estatística dos resultados foi efetuada, para a racionalização do trabalho, em segmentos distintos, sendo que o primeiro consistiu em avaliar os resultados provenientes do momento Rotina 1; a seguir, procedeu-se à avaliação dos resultados gerados no momento Qualificação 2 , então à avaliação dos resultados provenientes do momento Rotina 2 e, por fim ao estudo de identificação dos microrganismos detectados.

\section{Análise Estatística de "Rotina 1"}

Nesta etapa, os resultados avaliados foram gerados em classe B. Para avaliar possível correlação entre números de partículas viáveis e não-viáveis, calculou-se a média do número de partículas nos distintos locais (para cada tipo de partícula). A partir do logaritmo (base 10) destas médias, foram construídos os gráficos de dispersão da Figura 1.

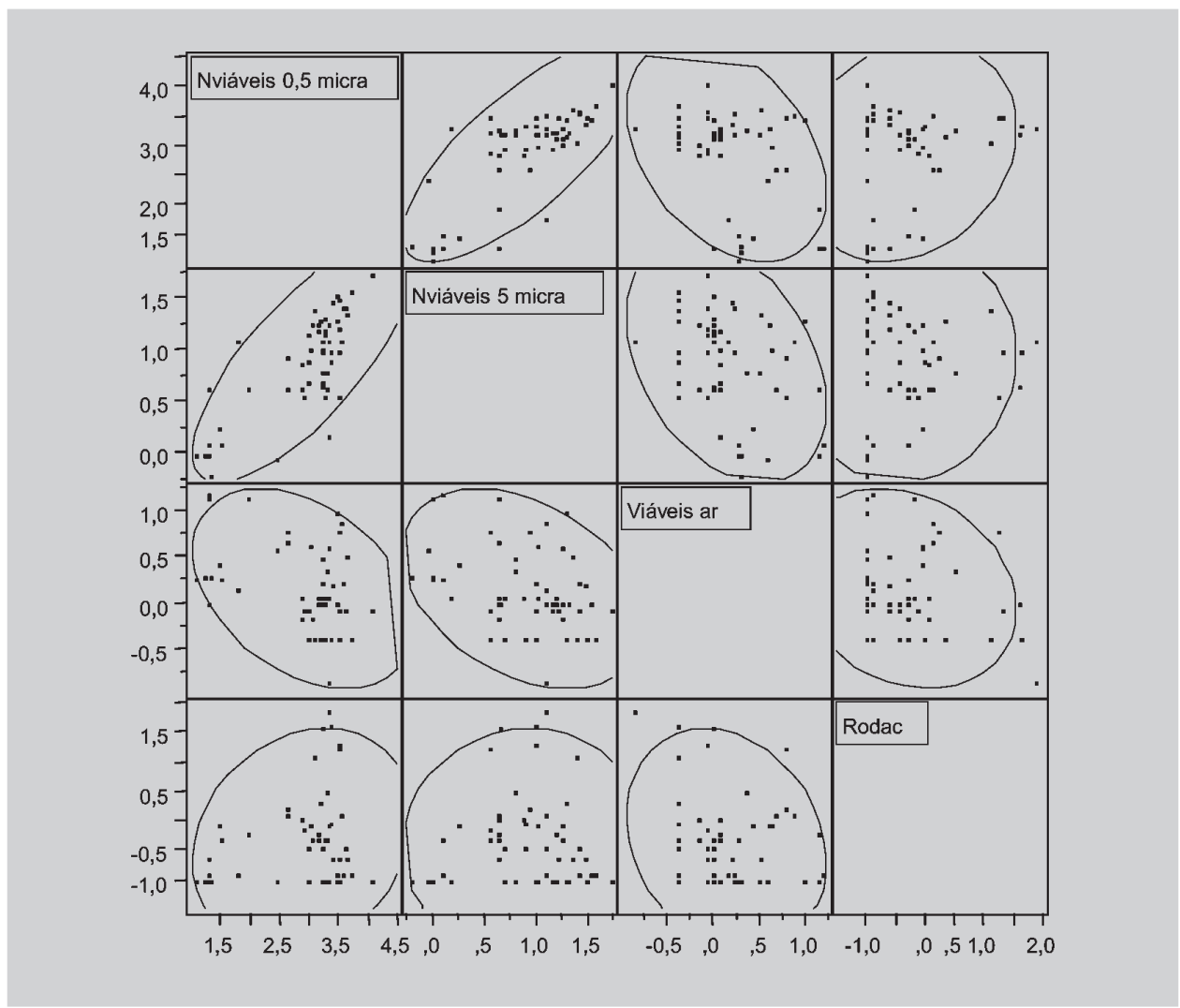

FIGURA 1 - Diagramas de dispersão do número médio de partículas viáveis e não-viáveis (média entre locais). 
Na Tabela I encontram-se os coeficientes de correlação entre os distintos tipos de partícula relativos aos resultados gerados no momento Rotina 1.

\section{Análise Estatística da "Qualificação 2"}

Os estudos foram realizados com um número grande de variáveis como local, posição, classe, sanitização, movimento (ou não) e em vários dias e para permitir melhor visualização das tendências, os resultados médios foram empregados na construção dos gráficos de perfil da Figura 2.

$\mathrm{Na}$ Tabela II encontram-se os coeficientes de correlação entre os distintos tipos de partículas, relativos aos resultados gerados no momento Qualificação 2.

TABELA I - Correlações entre o número médio de partículas viáveis e não-viáveis (média entre locais)

\begin{tabular}{lcccc}
\hline Variáveis & $\mathbf{R}$ & $\mathbf{r}^{\mathbf{2}} \mathbf{( \% )}$ & $\mathbf{P}$ & Conclusão \\
\hline Não-viáveis 0,5 $\mu \mathrm{m}$ x 5,0 $\mu \mathrm{m}$ & 0,7597 & 57,7 & 0,0000 & $* *$ \\
Não-viáveis 0,5 $\mu \mathrm{m}$ x Viáveis no ar & $-0,3832$ & 14,7 & 0,0039 & $* *$ \\
Não-viáveis 0,5 $\mu \mathrm{m}$ x Rodac & 0,2005 & 4,0 & 0,1421 & NS \\
Não-viáveis 5,0 $\mu \mathrm{m}$ x Viáveis no ar & $-0,3666$ & 13,4 & 0,0059 & $* *$ \\
Não-viáveis 5,0 $\mu \mathrm{m}$ x Rodac & 0,0531 & 0,3 & 0,7004 & NS \\
Viáveis no ar x Rodac & $-0,2100$ & 4,4 & 0,1238 & NS \\
\hline
\end{tabular}

** - Hipótese significante a 1\%; NS - Hipótese não significante; $r$ - fator de correlação; P - Probabilidade
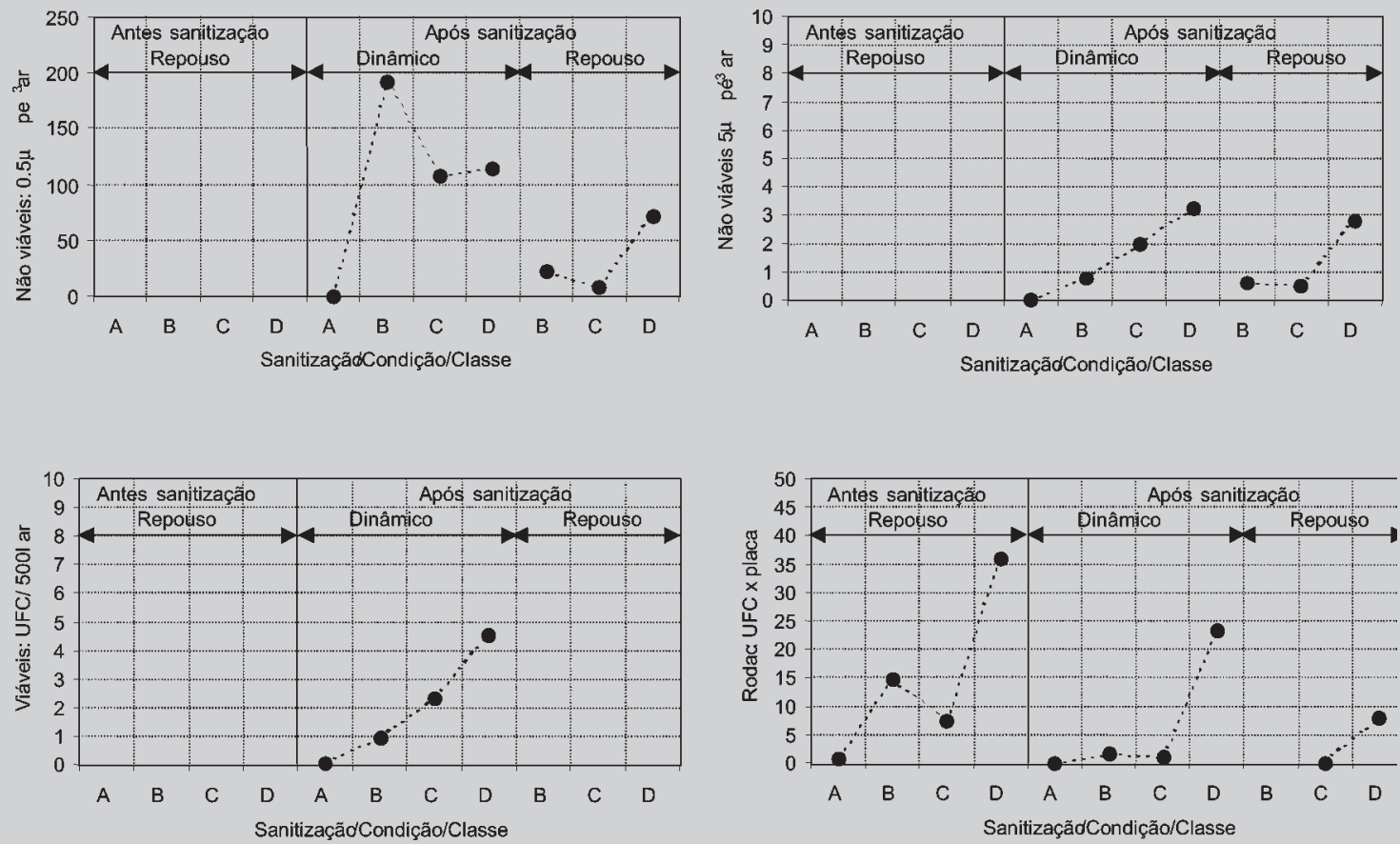

FIGURA 2 - Gráficos de dispersão dos resultados médios de contaminação, nas diferentes situações relativas ao momento Qualificação 2. 
TABELA II - Correlações entre o número médio de partículas viáveis e não-viáveis (média entre pontos e dias)

\begin{tabular}{lccccc}
\hline Correlação & $\mathbf{N}$ & $\mathbf{R}$ & $\mathbf{r}^{\mathbf{2}} \mathbf{( \% )}$ & $\mathbf{P}$ & Conclusão \\
\hline Não-viáveis 5 $\mu \mathrm{m}$ x Não-viáveis $0,5 \mu \mathrm{m}$ & 20 & 0,6908 & 47,7 & 0,0007 & $* *$ \\
Viáveis x Não-viáveis 0,5 $\mu \mathrm{m}$ & 10 & 0,5103 & 26,0 & 0,1318 & NS \\
Viáveis x Não-viáveis $5 \mu \mathrm{m}$ & 10 & 0,9224 & 85,1 & 0,0001 & $* *$ \\
Rodac x Não-viáveis 0,5 $\mu \mathrm{m}$ & 13 & 0,3569 & 12,7 & 0,2312 & NS \\
Rodac x Não-viáveis $5 \mu \mathrm{m}$ & 13 & 0,7417 & 55,0 & 0,0037 & $* *$ \\
Rodac x Viáveis & 12 & 0,8193 & 67,1 & 0,0011 & $* *$ \\
\hline
\end{tabular}

** - Hipótese significante a 1\%; NS - Hipótese não significante; N - número de amostragens; $r$ - Fator de correlação; P - Probabilidade.

\section{Análise Estatística dos dados da "Rotina 2"}

Observa-se que o tamanho das correlações aumenta com o aumento da classe: quando o número de microrganismos é pequeno, as correlações são muito baixas ou desprezíveis. Essa situação pode ser verificada na Tabela III.

Em uma área limpa a carga microbiana é usualmente muito baixa, o que dificulta a obtenção de resultados estatisticamente significantes (Ljungqvist, Reinmuller, 1993), como mostra a Figura 3.
Na interpretação do exposto, é interessante observar que foi possível detectar correlação entre partículas nãoviáveis e viáveis, o que se contrapõe com os resultados obtidos por Akers (1997). Ainda assim, é válido que se considerem as razões apontadas pelo autor, que certamente contribuíram para que também no presente trabalho as correlações fossem limitadas e nem sempre as mais perfeitas.

Algumas das razões descritas a seguir podem justificar a não-obtenção de correlação entre as contagens (Akers, 1997):

TABELA III - Correlações entre as variáveis em estudo dentro das classes A, B e C

\begin{tabular}{|c|c|c|c|c|c|c|}
\hline Classe & Correlação & $\mathbf{N}$ & $\mathbf{R}$ & $\mathbf{r}^{2}(\%)$ & $\mathbf{P}$ & Conclusão \\
\hline \multirow[t]{6}{*}{$\overline{\mathrm{A}}$} & Não-viáveis $5 \mu \mathrm{m}$ x Não-viáveis $0,5 \mu \mathrm{m}$ & 75 & 0,0000 & 0,0 & 1,0000 & NS \\
\hline & Viáveis x Não-viáveis $0,5 \mu \mathrm{m}$ & 75 & 0,0000 & 0,0 & 1,0000 & NS \\
\hline & Viáveis x Não-viáveis $5 \mu \mathrm{m}$ & 75 & 0,0000 & 0,0 & 1,0000 & NS \\
\hline & Rodac x Não-viáveis $0,5 \mu \mathrm{m}$ & 75 & 0,0304 & 0,1 & 0,7957 & NS \\
\hline & Rodac x Não-viáveis $5 \mu \mathrm{m}$ & 75 & 0,0000 & 0,0 & 1,0000 & NS \\
\hline & Rodac x Viáveis & 75 & 0,0000 & 0,0 & 1,0000 & NS \\
\hline \multirow[t]{6}{*}{ B } & Não-viáveis $5 \mu \mathrm{m}$ x não-viáveis $0,5 \mu \mathrm{m}$ & 375 & 0,4985 & 24,9 & 0,0000 & $* *$ \\
\hline & Viáveis x Não-viáveis $0,5 \mu \mathrm{m}$ & 375 & 0,1570 & 2,5 & 0,0023 & $* *$ \\
\hline & Viáveis x Não-viáveis $5 \mu \mathrm{m}$ & 375 & 0,0624 & 0,4 & 0,2282 & NS \\
\hline & Rodac x Não-viáveis $0,5 \mu \mathrm{m}$ & 375 & 0,0427 & 0,2 & 0,4092 & NS \\
\hline & Rodac x Não-viáveis $5 \mu \mathrm{m}$ & 375 & 0,0916 & 0,8 & 0,0764 & NS \\
\hline & Rodac x Viáveis & 375 & 0,1153 & 1,3 & 0,0256 & $*$ \\
\hline \multirow[t]{6}{*}{$\mathrm{C}$} & Não-viáveis $5 \mu \mathrm{m}$ x Não-viáveis $0,5 \mu \mathrm{m}$ & 75 & 0,6367 & 40,5 & 0,0000 & $* *$ \\
\hline & Viáveis x Não-viáveis $0,5 \mu \mathrm{m}$ & 75 & 0,2178 & 4,7 & 0,0606 & $*$ \\
\hline & Viáveis x Não-viáveis $5 \mu \mathrm{m}$ & 75 & 0,0699 & 0,5 & 0,5510 & NS \\
\hline & Rodac x Não-viáveis $0,5 \mu \mathrm{m}$ & 75 & 0,2651 & 7,0 & 0,0215 & $*$ \\
\hline & Rodac x Não-viáveis $5 \mu \mathrm{m}$ & 75 & 0,2056 & 4,2 & 0,0767 & NS \\
\hline & Rodac x Viáveis & 75 & 0,1051 & 1,1 & 0,3696 & NS \\
\hline
\end{tabular}

\footnotetext{
* - Hipótese significante a 5\%; ** - Hipótese significante a 1\%; NS - Hipótese não significante; N - número de amostragens; r- Fator de correlação; P - Probabilidade.
} 


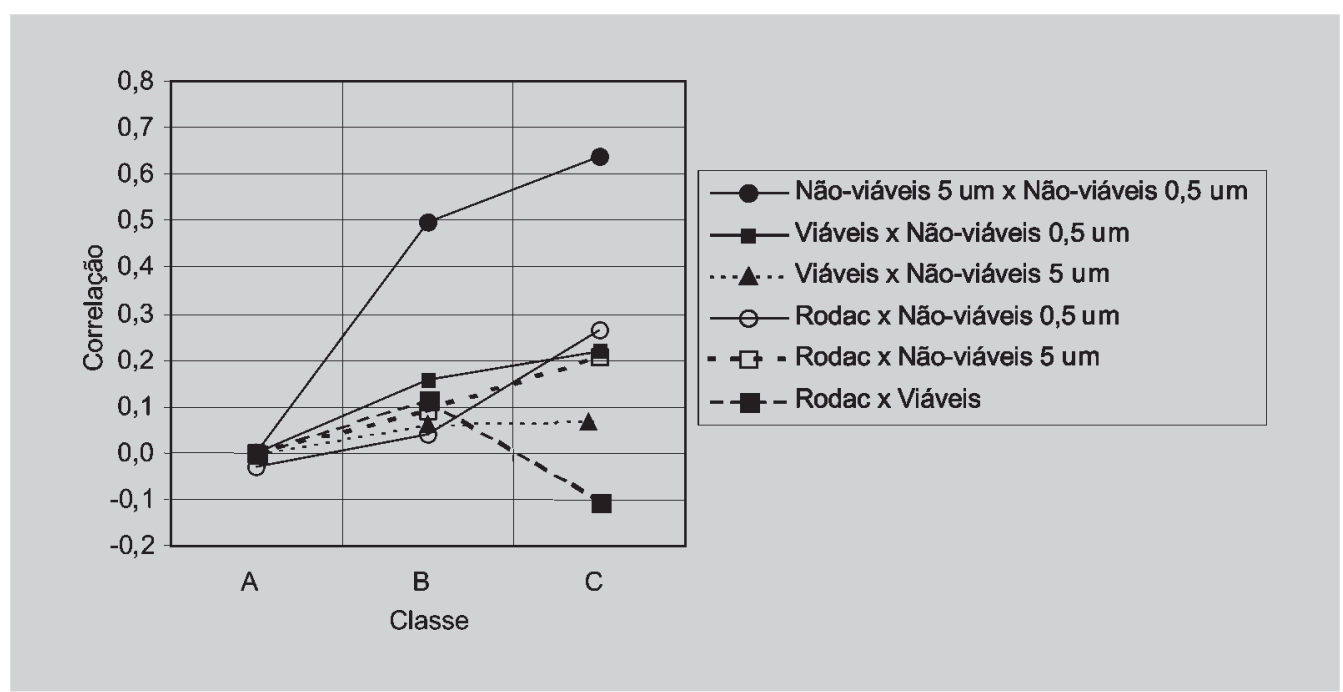

FIGURA 3 - Correlações entre parâmetros de avaliação para as classes A, B e C.

a) A entrada do ar para o interior de uma sala limpa classificada ocorre através de filtros HEPA, sendo que os mesmos operam em nível idêntico, tanto em salas limpas classe 10.000 quanto em salas limpas classe 100 . As diferenças constituem-se no número de trocas de ar por hora e também o movimento do ar dentro da sala. Aspecto a salientar é que as salas limpas são supridas com o ar submetido aos filtros HEPA, que possuem a mesma eficiência, independente da classe 100 ou classe 10.000. Considerando que não ocorre a entrada de ar por outras vias, não há razão para que salas limpas classe 100 tenham menor número de partículas viáveis que salas limpas classe 10.000 .

b) O fator que controla o número de partículas viáveis, ou seja, o controle da contaminação nestas salas, baseiase na habilidade dos operadores em trabalharem sem promover contaminação, pelo domínio da técnica asséptica no desempenho das tarefas designadas.

c) É impossível que um engenheiro de salas limpas desenhe e construa uma sala limpa considerando os fatores ambientais e pessoas, pois estas fogem de seu controle. O lay out da sala e a qualificação das pessoas que irão trabalhar nessa sala ficam fora de seu controle, portanto, as salas limpas podem conter baixo nível de partículas não-viáveis, mas não obrigatoriamente baixo número de partículas viáveis. A utilização de recursos como os filtros HEPA garantem reduzido número de partículas, mas não garantem baixas contagens de microrganismos. O ideal seria a ausência do operador no processo, evitando, assim, possível contaminação.

d) Salas limpas com manutenção adequada, geralmente, não apresentam altos níveis de contaminação micro- biana. Isto se deve a fatores como programa de sanitização das salas limpas, alinhados com a técnica asséptica dos operadores, e também ao fato de que os microrganismos precisam de fontes de carbono e fonte de energia para se multiplicarem, sendo, portanto, rara a sua colonização nos dutos de ar.

Considerando o Federal Standard 209 E e a United States Pharmacopeia, é incorreto pensar que existe um paralelo preciso entre as contagens de partículas não-viáveis e partículas viáveis (USP 25, 2002). No entanto, é correto dizer que a "qualidade microbiana" será melhor numa sala limpa, onde o número de partículas não-viáveis apresenta menor número, de acordo com sua classificação. Existem diversos fatores que afetam o nível de partículas viáveis nas salas limpas, entre eles o pessoal. Portanto, as salas limpas podem ser classificadas apenas utilizando as contagens de partículas não-viáveis (Akers, 1997; USP $25,2002)$, desde que se mantenha em mente a complexidade de sua interpretação.

\section{Estudo dos microrganismos presentes por classe de sala limpa}

Quanto às bactérias obtidas nas amostragens efetuadas no presente trabalho, observa-se que $49(11,8 \%)$ foram bactérias gram-negativas, geralmente mais suscetíveis à desidratação (Whyte, Niven, 1986).

Os microrganismos mais comuns foram: Bacillus $\mathrm{sp}$, Staphylococcus sp, Corynebacterium $\mathrm{sp}$ e Staphylococcus haemolyticus. No total estes quatro microrganismos estiveram presentes em aproximadamente $80 \%$ das determinações, como mostra a Tabela IV e a Figura 4. 
TABELA IV - Microrganismos detectados, em apresentação respeitando a ordem de incidência

\begin{tabular}{llcc}
\hline Microrganismo & Morfologia & $\mathrm{n}$ & $\%$ \\
\hline Bacillus sp & Bacilo G+ & 119 & 28,67 \\
Staphylococcus sp & Coco G+ & 93 & 22,41 \\
Corynebacterium sp & Bacilo G+ & 70 & 16,87 \\
Staphylococcus haemolyticus & Coco G+ & 46 & 11,08 \\
Staphylococcus xylosus & Coco G+ & 15 & 3,61 \\
Alcaligenes xilosoxidans & Bacilo G- & 14 & 3,37 \\
Flavobacterium sp & Bacilo G- & 11 & 2,65 \\
Flavobacterium breve & Bacilo G- & 9 & 2,17 \\
Enterococcus casseliflavus & Coco G+ & 7 & 1,69 \\
Pseudomonas stutzeri & Bacilo G- & 6 & 1,45 \\
Pseudomonas sp & Bacilo G- & 5 & 1,20 \\
Staphylococcus auricularis & Coco G+ & 5 & 1,20 \\
Micrococcus luteus & Coco G+ & 4 & 0,96 \\
Staphylococcus epidermidis & Coco G+ + & 0,96 \\
Comamonas acidovorans & Bacilo G- & 4 & 0,72 \\
Staphylococcus cohnii & Coco G+ & 3 & 0,72 \\
Stenotrophomonas maltophilia & Bacilo G- & 3 & 0,24 \\
Total & & 1 & 100,00 \\
\hline
\end{tabular}

$\mathrm{G}=$ Gram; $\mathrm{n}=$ número de identificações

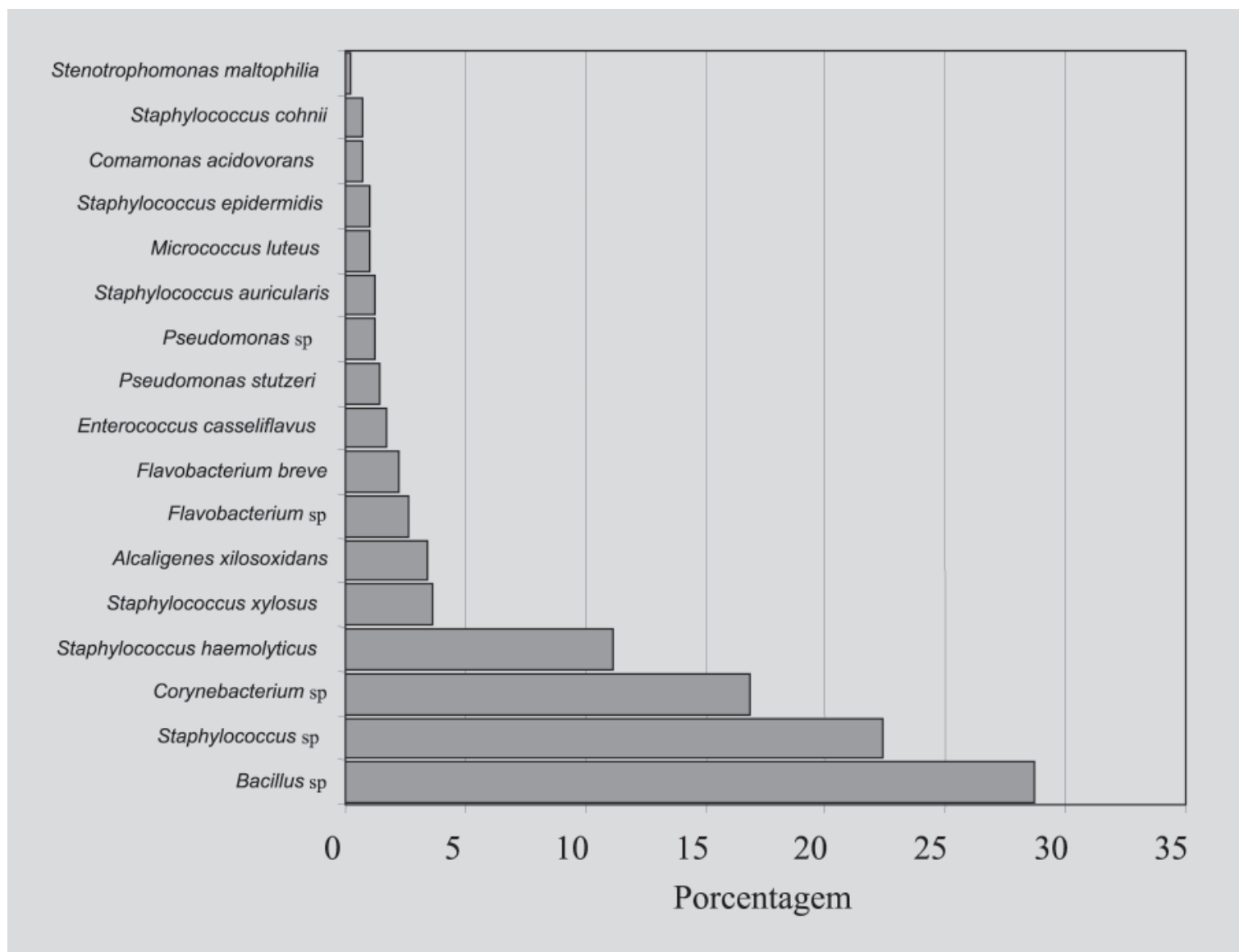

FIGURA 4 - Histograma de freqüência dos microrganismos encontrados em salas classe B, C e D. 


\section{CONCLUSÃO}

1 - A situação após sanitização evidenciou redução intensa no número de partículas viáveis de superfícies $\operatorname{Rodac}^{\circledR}$ (Figura 2).

2 - Existe correlação entre partículas viáveis e não-viáveis de 5,0 $\mu \mathrm{m}$, no ambiente (Figura 3).

3 - A situação dinâmica não provocou elevação uniforme no número de partículas viáveis de superfícies Rodac $^{\circledR}$ (Figura 2).

4 - A situação dinâmica apresentou correlação entre partículas viáveis do ambiente e o nível decrescente de limpeza da sala $(A \Rightarrow D)$ (Figura 2).

5 - Os valores de correlação obtidos entre partículas nãoviáveis de 0,5 e $5,0 \mu \mathrm{m}$ e viáveis aumenta proporcionalmente com o nível de sujidade da área $(\mathrm{A} \Rightarrow \mathrm{D})(\mathrm{Fi}$ gura 2).

6 - Em relação à identidade dos microrganismos, os mais freqüentes foram Bacillus sp, Staphylococcus sp e Corynebacterium sp (Tabela IV e Figura 4).

\section{ABSTRACT}

\section{Clean rooms: a correlation study between viable and non-viable particles}

This paper presents a study about environmental monitoring data for cleanrooms ( $A, B, C$ and $D$ classified areas). The parameters that were compared are: total airborne particles of 0.5 and $5.0 \mu \mathrm{m}$, airborne colony forming units (CFU'S) and CFU's on surfaces (Rodac $\left.{ }^{\circledR}\right)$. In these areas sampling was performed "at rest" and "dynamic" conditions, before and after sanitization and during certification and routine basis. Available data in literature indicates that the parameters are not particularly dependent upon the lay out or classification of areas, but rather on the use of the areas, and the operators behaviour. Evaluating the data, the conclusion was about a correlation among different sampling places, for total airborne particles of 0.5 and $5.0 \mu \mathrm{m}$, and absence of this kind of correlation in laminar flows positions. Also, correlation values were always increasing with the cleanless of the environment. The microrganisms most frequently isolated in areas $B, C$ and $D$ were Bacillus $s p$, Staphylococcus sp and Corynebacterium $s p$.

UNITERMS: Clean rooms. Environmental monitoring. Viable particles. Nonviable particles. Microrganisms.

\section{AGRADECIMENTOS}

Os autores agradecem a Eli Lilly do Brasil LTDA pelo apoio recebido para o desenvolvimento do presente trabalho de pesquisa.

\section{REFERÊNCIAS BIBLIOGRÁFICAS}

AKERS, J. E. Environmental monitoring and control proposed standards, current practices, and future directions. J. Parenter. Sci. Technol., Philadelphia, v.51, n.1, p.36-47, 1997.

INSTITUTE of Environmental Sciences. Federal standard 209 E: airborne particulate cleanliness in cleanrooms and clean zones. Mount Prospect: IES, 1992. 48p.

INSTITUTE of Environmental Sciences and Technology, IEST-RPCC-0062: testing clean rooms. Mount Prospect: IES, 1992.35p.

LJUNGQVIST, B.; REINMULLER, B. Interaction between air movements and the dispersion of contaminants: clean zones with unidirectional air flow. J. Parenter. Sci. Technol., Philadelphia, v.47, nº.2, p.60-69, 1993.

UNITED STATES Department of Health and Human Services. Food and Drug Administration. Center for Drug Evaluation and Research. Guideline on Sterile Drug Products Produced by Asseptic Processing: Topic 3: Environmental Monitoring. In: Guidance for Industry. Rocksville: the United Pharmacopeial Convention, p. 535-599, 2002. (PDA/USP Joint Conference on Sterile Products Manufacturing, May 2002).

UNITED STATES PHARMACOPEIA. 25 ed. Rockville: United States Pharmacopeial Convention, 2002. p.22062212.

WHYTE, W.; NIVEN, L. Airborne bacteria sampling: the effect of dehydration and sampling time. J. Parenter. Sci. Technol., Philadelphia, v.40, n.5, p.182-187, 1986.

Recebido para publicação em 19 de fevereiro de 2003. 